\title{
FDA announces reforms of drug review process
}

\section{- Agency to use industry Washington}

OVERWORKED and criticized by activists who say that drug approval delays cost lives, the US Food and Drug Administration (FDA) announced last week major new reforms to speed its reviews of new pharmaceuticals. While the agency will continue to use its own inspectors to review innovative or badly needed drugs, it will hire outside contractors - many of whom are expected to come from the pharmaceutical industry - to review more routine products.

Although the pharmaceutical industry last week hailed the reforms as long-needed changes that will reduce both the cost of new drugs and their delay in reaching market, critics warned that use of industry essentially to police itself risked conflict of interest. And in a 13 November letter to FDA commissioner David Kessler, Representatives John Dingell (Democrat, Michigan) and Henry Waxman (Democrat, California) and Senator Edward Kennedy (Democrat, Massachusetts) raised concerns that the reforms are "thinly veiled efforts to weaken the agency".

Pharmaceutical companies have long complained about the backlog in the FDA drug approval process - on average, it now takes 9.75 years for a drug to be developed and approved. By focusing its internal review efforts on the most important drugs, a new procedure the agency calls "accelerated approval" and aims to have in place by 1994, FDA hopes to reduce that period to 5.5 years. For more routine drugs, which will be reviewed by a combination of internal staff and contractors, FDA intends to cut almost three years off the process of development and approval, to an average of seven years.

In a rare convergence of interests, the new proposals have the effect of answering the demands of both industry and disease activists. AIDS groups, in particular, have been vocal in their criticism of FDA for delays in approving experimental AIDS therapies. But it was the mounting concerns of the biotechnology and pharmaceutical industry that finally goaded the Administration into action. The reforms come not from FDA itself, but from the White House Council on Competitiveness, a body headed by Vice President Dan Quayle that is devoted to ensuring that government does not interfere unduly with industry (see Nature 353 , 199; 19 September 1991).

But to the reform's Congressional critics, the moves smack of politically moti- vated deregulation, with potential harm to public health. Despite a series of generic drug scandals that pointed out weaknesses in FDA's internal controls, the agency has remained understaffed and poorly funded in the Administration's annual budget request, the critics note.

Other opponents of the moves argue that FDA will find it difficult, if not impossible, to retain enough conflict-free outside researchers to review the volumes of scientific and clinical-trial data that companies must submit with their drug applications. "There isn't an independent group of contractors out there. They're going to have to go to industry, and I think that's dangerous," says Margaret Mellon, director of the National Wildlife Foundation's Biotechnology Policy Center.

The Competitiveness Council plan states that FDA will "establish safeguards to avoid the appearance of conflict of interest and prevent the opportunity for a company to influence the outcome of the external review." But council officials say that this does not mean new regulations; they believe that existing conflict-of-interest rules are sufficient to ensure that independent reviewers are not materially interested in the drugs they evaluate. They also note that both France and the United Kingdom already rely heavily on outside reviewers in approving new drugs.

The new FDA reforms will also:

- allow Institutional Review Boards the panels of scientists at universities or companies who currently review research protocols at their own institutions - to approve phase I clinical trials of new drugs under study. This will let FDA safely ignore much of the initial clinical research for new therapies, in favour of focusing on those therapies that have passed the first test and are more likely to become commercial products.

- relax the standards for efficacy to take into consideration the risk to health that delaying a drug for further testing may entail. Based on policies that FDA has already started to use for some AIDS drugs, this change essentially argues that as long as a potentially life-saving therapy is not dangerous, it is better to have it available while researchers determine its efficacy than withhold it for years of further clinical trials.

- take into consideration approval of drugs in other countries. FDA is now negotiating with the European Communities to develop common standards for clinical trial, data formats and animal testing.
By the end of the process, FDA hopes to be able to automatically approve drugs for sale in the United States if they have already been approved by the EC.

Although some of the reforms can be implemented by simply changing internal FDA policy, most will require formal rulemaking procedures — including public comment periods - and some will need new congressional legislation before they can take effect. Christopher Anderson

\section{SCIENTIFIC MISCONDUCT}

\section{Tables turned}

\section{Washington}

ANYONE who has ever contemplated the sobering prospect of an investigation by Representative John Dingell (Democrat, Michigan) or an inquiry by freelance science cop Walter Stewart can appreciate the irony: Stewart, backed by an attorney representing Dingell's committee, was himself grilled last month in a day-long deposition, and he invoked 'executive privilege' 41 times in refusing to answers questions posed by an attorney representing one of the targets of his investigations.

The case at issue was that of $L$. Cass Terry, a Medical College of Wisconsin neurologist who is the subject of an investigation by the National Institutes of Health (NIH) misconduct office (see Nature 349, 357; 31 January 1991). Terry's lawyer, Matthew Flynn, is pulling out the stops in his client's defence - beyond arguing that Terry was set up by an angry employee, Flynn is charging that NIH's misconduct policies are illegal, and that Stewart violated his client's rights by leaking secret information about the case to the press.

In the course of Flynn's questioning, which veered wildly through Stewart's undistinguished history as an NIH physicist to his motivations for switching to misconduct as a research subject, Stewart managed to forget the name of the NIH institute that employs him (it is the National Institute of Diabetes and Digestive and Kidney Diseases), and was spared only by an objection from his lawyer from having to discuss whether he suggested that a certain whistle-blower hide a microphone in her underwear. But throughout, he defended his misconduct work as a simple research pursuit, as valid as any other.

Charles Tiefer, Stewart's congressional attorney, says that executive privilege (also known as 'speech and debate privilege') is designed to protect legislators from being sued for possibly slanderous things they may say in session. The Supreme Court, he says, has ruled that the privilege can be extended to the working of any congressional investigation, such as the Dingell probes in which Stewart participated. Without the opportunity to occasionally hide behind this legal protection, he says, Congress would be unable to conduct investigations. Christopher Anderson 